\title{
An exploratory network analysis of hot people and places*
}

\author{
Andrew P. Wheeler ${ }^{1, * *}$, Sarah J. McLean ${ }^{1}$, Robert E. Worden ${ }^{1,2}$
}

*This work is in collaboration with the Albany, NY Police Department (APD) and the John F. Finn Institute for Public Safety. This project is supported by Award No. 2013-MU-CX-0012, awarded by the National Institute of Justice, Office of Justice Programs, U.S. Department of Justice. This work was also presented as a NIJ research presentation at the International Association of Crime Analysts in Denver, Colorado, 2015. The opinions, findings, and conclusions or recommendations in this report are those of the authors and do not necessarily reflect those of the Department of Justice.

**Corresponding author, email: apwheele@gmail.com

1. John F. Finn Institute for Public Safety, 421 New Karner Rd., Suite 12, Albany, NY 12205 518-456-6323

2. School of Criminal Justice, University at Albany, SUNY

Andrew $P$. Wheeler is a recent PhD graduate from the School of Criminal Justice at SUNY Albany, and is currently a senior research analyst at the John F. Finn Institute for Public Safety. His research focuses on the spatial analysis of crime at micro places, and he collaborates with multiple police departments in the capital region of New York State. His recent work has been published in the Journal of Quantitative Criminology, Cartography and Geographic Information Sciences, and the Journal of Investigative Psychology and Offender Profiling.

Sarah J. McLean bio.....

Robert E. Worden bio.... 
Title: An exploratory network analysis of hot people and places

Abstract: There is a growing body of evidence that suggests police can be more effective in addressing crime and disorder when they focus on hot people and/or hot places -- those people and places disproportionately driving crime and disorder. I examine the connections between hot people and hot places by considering micro places (street segments and intersections) and people as nodes in an interconnected network. Specifically, I examine whether hot people tend to have a finite set of locations they congregate, and whether hot places have unique profiles of chronic offenders. The end goal is to identify if observed patterns can help police combine targeted enforcement of hot people and hot places in one overarching strategy.

Keywords: network, chronic-offender, hot-spots, street-units

\section{Introduction}

Two of the most successful and widely implemented intelligence lead policing strategies are targeting hot spots of crime and targeting chronic offenders (Ratcliffe, 2008). This is based on the logic that the majority of crime is committed in a minority of places and synonymously that the majority of crime is committed by a few offenders (Spelman, 1995; Weisburd, 2015). This article presents findings from an exploratory analysis designed to diagnose the extent to which hot people and places overlap. For instance, do hot spots of crime also tend have a large proportion of chronic offenders committing crimes there? And do chronic offenders tend to limit the majority of their activity to a small number of hot spots?

To the extent that either of these questions are answered in the affirmative, it would suggest that police could gain even more purchase were they to focus their efforts at the intersection of hot people and hot places. Such that either when a place based hot spot is identified, regular offenders at that location should be identified and can be a potential target for police enforcement. On the flip-side when chronic offender lists are made, the regular locations that an offender commits crime should be targets for place based interventions.

To assess these propositions, I conduct an exploratory analysis by considering people and places as nodes in an interconnected network. For the analysis I use incident reports in Albany, NY between 2000 through 2013 to connect people to the places where they commit their offenses. The analysis will be focused mainly on trying to identify general patterns in the data, and whether those patterns suggest particular policing interventions are appropriate.

I first present a literature review focused on three topics. The first is crime pattern theory, which describes how people move and behave in the network of places. The second focuses on network analysis as it has been used in criminal justice, which typically has been limited to the examination of the connections between co-offenders. The third reviews a few prior attempts to have offender focused targeted interventions at particular locations and their relative success.

I then present three separate analyses. The first focuses on people and the places they commit crimes. For example, do offenders tend to only commit crime in a few places? And what is the typical extent of where offenders commit crime? The second focuses on places, and attempts to identify whether certain places can be characterized by the diversity of offenders committing crime. This information is useful to identify if particular locations are disproportionately crime hot spots due to only a few offenders. The 
third focuses on neighborhoods and boundaries, and in particular tries to identify if any meaningful neighborhood boundaries can be identified within the data itself. Identifying neighborhood boundaries within the data will attempt to address the modifiable area unit problem. Instead of relying on a fixed spatial unit, such as street segments and intersections, can specific areas that have a core set of offenders be identified just by looking at the network connections?

\section{Crime Pattern Theory}

Crime pattern theory is a theory describing the observed spatial patterns of offending (Brantingham \& Brantingham, 1993). It is based on the premise that offenders gain knowledge of potential victims through their routine activities. For example, an offender might observe potential homes to burglarize on their way to-and-from work (Rengert \& Wasilchick, 2000). Because of this, spatial crime patterns tend to cluster in the same places there are simply more people.

This allows one to predict future crime locations based on some simple observations of past behavior. The most obvious being that offenders tend to commit crimes nearby previous offenses in time and space (Hering \& Bair, 2014; Lammers et al., 2015; Johnson et al., 2009), but can also be predicted based on external factors such as the street network (Reid et al., 2014) or locations that attract many people, like shopping malls (Frank, Andresen \& Felson, 2012; Frank, Andresen \& Brantingham, 2012).

A related theory of offender spatial behavior is that they forage for new opportunities, like animals (Jacobs, 2010; Johnson et al., 2009). This offender behavior would result in that the initial seeds of locations an offender is aware of are provided by their past routine activities, but that in search for new targets they will continually expand the area of their search outward from these initial locations. This would result in continual spatial expansion over time from a small area to a progressively larger offending range.

\section{Network Analysis in Criminology}

The major domains of network analysis within criminology and criminal justice are related to cooffending and criminal groups (McGloin \& Kirk, 2010). Criminal groups may be formalized networks, such as drug cartels (Sparrow, 1991), or they may be more informal youth gangs (McGloin, 2005). Individuals within such groups may or may not be co-offenders. More generally, co-offending, the act of committing a crime in coordination with multiple people, is very common. But co-offending is often ephemeral compared to gang activity (Iwanski \& Frank, 2013).

Network analysis can be categorized in three broad areas (Papachristos, 2011):

1) What is the shape of the network?

2) Why are certain nodes connected to other nodes?

3) What affect does one node have on other connected nodes?

1 - What is the shape of the network? - tries to answer questions such as "Is the network entirely connected?" or "Are there many isolated communities within the network?". If a network is entirely connected it may be small world. The concept of small world is where the game 6 degrees of separation takes its motivation, in that it often takes very few steps for any two nodes in the network to reach one another (Kadushin, 2012). 
Most real world networks have communities in which ties are dense, but then have a few nodes who connect together larger communities. These nodes may not be as embedded in the specific communities as others, but have influence in that they can act as a bridge between different larger communities (Granovetter, 1973).

The shape of the network is often assessed by drawing the network with a set of points and lines showing the nodes and their interconnections (McGloin, 2005). If the network is small enough one can often identify the characteristics of bridges, different communities, or whether the network is small world simply by the drawing. Different centrality metrics though are often used to identify bridges in the network (Morselli, 2012).

2 - Why are certain nodes connected to other nodes? - tries to identify characteristics that predict when one person is more or less likely to be connected to another. A predominate theme in networks is the concept of homophily, that birds of a feather flock together. Most co-offenders and youth gangs tend to be composed of people of the same sex, and race, and similar in age (Van Mastrigt \& Carrington, 2013). For another example, interconnections among gang rivalries tends to be related to, but not entirely redundant with geography (Tita \& Randil, 2011). Brantingham et al. (2012) find that gang violence tends to be concentrated on borders where gang territories meet. Lantz \& Ruback (2015) show that repeat burglary victimizations are not only a function of the same offender on multiple occurrences, but also that other connected co-offenders are more likely to victimize the same location.

3 - What affect does one node have on other connected nodes? - is the idea that doing something to one node can cause subsequent things to happen to other nodes. In networks of intravenous drug users diseases such as hepatitis or HIV can spread from sharing needles. In criminal networks one can try to disband a gang by removing key figures (McGloin, 2005; Morselli, 2010). Braga et al. (2013) show in a focused deterrence strategy that targeting certain gangs can reduce crime in other connected gangs.

We can take these lessons from network analysis of people to attempt to make decisions about how to allocate police resources spatially. For instance, the fact that the border of gang rivalries are more likely to host violence makes them a more suitable target for crime prevention through environmental design interventions than where gang members tend to hang out (Tillyer \& Kennedy, 2008).

Places themselves may be highly interconnected among many people, and so targeted strategies at these locations may have the widest deterrent effect among many people. But these may be the areas with the most potential for crime displacement or the hardest to have an overall effect. An area that has only a small number of people operating is likely to be more affected by the arrests of those few individuals.

Flipping the focus on people, people who have few interconnections among places may be the easiest to deter by targeted enforcement strategies at one location. For example, Weisburd and Green (1994) identify clusters of drug hot spots at intersections in Jersey City, and show that dealers very rarely have criminal histories in multiple hot spots. This suggests targeted intervention at one of the hot spots is likely to deter those drug dealers, and is unlikely to displace them to unfamiliar territory. But, many chronic offenders have wide spatial footprints (Spelman, 1990), suggesting that their behavior will be easily displaced if an intervention only focuses on one area.

\section{Prior chronic people at places strategies}


Problem-oriented policing strategies often identify particular chronic offenders as problems (Eck and Spellman, 1987). There are a few prior published evaluations of crime reduction strategies that have both hot places and hot people components simultaneously. Those few examples follow.

Corsaro et al. (2012) in a focused deterrence strategy identified particular locations where violent and drug hot spots overlapped, and then invited low level drug dealers from those locations to call-ins. Corsaro et al. (2012) found a modest reduction in violent crime among the hot spots that had the most violence to begin with.

Uchida \& Swatt (2013) describe an evaluation of separate place and chronic offender strategies. The chronic offender strategy focused on disseminating intelligence through bulletins on specific chronic offenders, while the place based strategy focused on more traditional increases in police presence through directed patrol. They found that reporting districts who did both offender and place based strategies had reductions in crime, but other districts who only did one intervention had no effect on crime.

Groff et al. (2015) evaluated the crime reduction benefits of foot patrol, problem oriented policing, or offender focused policing in crime hot spots. They found that offender focused policing reduced violent crimes by over $50 \%$, whereas the other two interventions were not statistically significant. The offender focused strategy had a set of dedicated officers, who with centralized intelligence identified chronic offenders with a prior history of violent offenses. These specialized officers then targeted the specific offenders through field contacts and surveillance.

These prior evaluations show modest decreases in crime by combining both offender and location based strategies compared to separate interventions (although each of the strategies are quite different). But they also show that the prior implementations as described were not implemented in an integrated fashion. In each a sequential process was 1 ) identify geographic hot spots, and then 2 ) identify the hot people within the hot spot.

What the benefit of considering both people and places as an interconnected network brings to targeted enforcement is the consideration that people and places are not simply in separate bubbles. For example, chronic offenders within one hot spot are not likely to only commit crime within that one hot spot. While geographic displacement from targeted enforcement is rare (Bowers et al., 2011; Guerette \& Bowers, 2009) these evaluations invariably only compare displacement to nearby spatial locations. Offender behavior shows that sequential crimes are not often restricted to within a small distance (Wheeler, 2012), and so displacement of people is more likely to occur in these other activity spaces along the network that are not necessarily nearby in space.

An example might be a drug offender has three places where he sells. Locations of where drugs are sold are often dictated by market forces, such as having a location where there is appreciable foot traffic (St. Jean, 2007). If targeted enforcement occurs at one, he is likely to simply move to one of the other two locations in which he has sold previously. He is unlikely to try to find a new place nearby the old sales place, as other places nearby unlikely have the necessary foot traffic to find customers. None of the three evaluations reported an analysis of the deterrence of identified chronic individuals, so although crime was reduced in the targeted areas, it is unknown if those specific targeted offenders were deterred from committing crime or displaced to separate locations. 
Given the interconnectedness of the network, there are likely certain places that are more amenable to offender based strategies, and there are likely certain people who are more amenable to place based strategies. A drug dealer that only sells drugs in one location is more likely to be deterred when targeting that one location. An arrest focused strategy is more likely to work in a place where only a few offenders operate. In a hot spot of crime with many offenders an arrest based strategy is unlikely to have an appreciable effect. A chronic offender is more likely to be displaced to prior activity areas, as opposed to unknown new places nearby in space. The goal of this exploratory study is to identify to what extent such patterns occur for people and places.

\section{Data Description}

This analysis is based on reported crime incident data completed by the Albany Police Department from 2000 through 2013. Albany is the capital of New York State, has a population of around 100,000 individuals, and the police department has around 330 sworn officers.

Because the analysis requires identifying unique individuals and identifying the exact location of an incident, only incidents that include a named suspect or arrested offender and a precise address are included in the analysis. Names are associated through a master name index in the APD records management system. The geocoding hit rate for both incidents and field intelligence cards is over $98 \%$, and is consistently high throughout the study period.

The spatial units of analysis are called street units, intersections and street midpoints. Incidents were geocoded to the address level and then assigned to the nearest street unit. Over the study period there are over 4,000 street units in Albany with at least one reported offense throughout the study period.

\section{People Profiles}

Using street units as the spatial unit of analysis, I took offenders linked to places and counted up the total number of offenses, along with the number of unique street units at which they committed crimes. In the fourteen years analyzed, there were a total of 32,092 offenders linked to 88,099 separate offenses. Of all offenders, 14,810 offenders (46.1\%) only committed one offense. Of course individuals with only one offense can only have a recorded crime at one street unit, but how about offenders with more than one offense? Figure 1 plots the mean proportion number of locations/number of offenses along with the $95 \%$ confidence interval of that mean. So an offender with a total of 2 offenses can either have 1 location or 2 locations they committed crimes at. Since the value for 2 offenses is around 0.9 , this means that around $90 \%$ of those offenders committed crimes at 2 locations. For the 3,265 offenders with three offenses, 2,099 (64.3\%) have three separate locations, 868 have 2 locations (26.6\%), and 298 $(9.1 \%)$ have one location. This results in $(2099 * 3+868 * 2+298)=8,331$ locations. And the maximum total of separate locations could be $3265 * 3=9795$, resulting in a percentage of $8331 / 9795=0.85$. Relating this to typical network analysis jargon, Figure 1 is the normalized degree centrality of individuals, averaged for individuals with different numbers of offenses.

This particular pattern certainly suggests non-random spatial clustering. If one is randomly picking locations in the city to commit a crime, and the probability of any particular location in the city is say 0.01 , the probability of picking that same location again would be only 0.0001 . The probability of selecting a particular street unit for a crime based on the citywide proportions of crime are all lower than 0.01 , and even correcting for multiple comparisons one would not expect any more than a few repeat locations among the sample. 
[INSERT FIGURE 1 HERE]

But, this simultaneously suggests that street units may be too small of a location to identify an offender's typical territory. For example for 20 offenses, an offender typically has committed offenses at around 12 separate street units. If someone focused a particular strategy at simply one of these locations, presumably displacement is likely to occur to another location the offender has previously committed a crime at, or that one is unlikely to even expose a particular offender to the intervention. But theoretically, one could make the spatial units infinitesimally small, and then offenders would always commit crime at a new location. So discretizing the spatial unit and counting up the repeats like this is potentially misleading, as offenders may commit crimes not at the exact same location, but nearby their prior offenses (Lammers et al., 2015). But how should one identify an area that reasonably characterizes where offenders commit their crimes at?

Plotting the individual offending spatial footprints showed tremendous spatial heterogeneity. This partially confirms the observation in Spelman (1990) that chronic repeat offenders tend to commit crime in a wide variety of places. But a common pattern to emerge was a visible cluster at one location with a few outlying locations. This is consistent with animal tracking studies (Mizutani \& Jewell, 1998), in which the longer one tracks an animal the larger the boundary of those points will become, but the density of the points are greater in a smaller area. This is similar to common foraging strategies in which animals have many small moves, but on occasion have one large jump in between sequential points (Brantingham \& Tita, 2008).

To identify these clusters I calculated the minimum spanning tree for a set of points, and then cut the tree at any location where the branch was over 1,000 meters. Cutting the tree at this arbitrary value was intended to prevent the measure from being biased from the long jumps mentioned - which are likely outlier crime locations compared to an offender's historical footprint.

Figure 2 shows a random set of 12 offender footprints (that had at least 5 crimes), with the minimum spanning tree drawn as light grey lines, and separate clusters per offender shown as different point symbols and colors. The minimal spanning tree was chosen because many clusters of points appeared to be stringy and run along a line of locations (Wilkinson \& Wills, 2008), and the clusters were different sizes. The stringiness is likely a function of the street network, e.g. a set of crimes following a particular length of a street. This makes the use of partitioning types of clustering solutions (like k-means) seem less appropriate (Ester et al., 1996), and using the minimal spanning tree allows the clusters to be irregular in shape (Wu \& Grubesic, 2010). While such a clustering procedure is ad-hoc and does not always produce logical results, it appears to work reasonably well for many offenders. Such a pattern suggests that the DBSCAN clustering algorithm may perform well (Ester et al., 1996), as well as single linkage hierarchical clustering (as it is equivalent to the minimum spanning tree).

\section{[INSERT FIGURE 2 HERE]}

Using this criteria to cluster offender footprints, the offenders tended to have multiple clusters of offenses. Of the 3,483 offenders with over 5 crimes, $11 \%$ had one group, $25 \%$ had two groups, $32 \%$ had three groups, $21 \%$ had four groups, and the remaining $11 \%$ had 5 or more clusters. But even though the majority of offenders had multiple spatial clusters of offenses, they tended to commit the majority of their crimes at only one or two of these clusters. 
Figure 3 is a jittered scatterplot of the proportion of offenses within a cluster, separating the clusters by color. So for offenders with only 1 cluster, 100\% of their offenses are in that single cluster, but for 2 groups the majority of the distribution is mainly between $60 \%$ and $90 \%$ of an offender's crime in the biggest cluster. For three cluster groupings the top group tends to contain $50 \%$ to $70 \%$ of their crimes, while there are less separation between the $2^{\text {nd }}$ and $3^{\text {rd }}$ cluster. By the time one gets to 4 groups there appears be essentially no separation between the higher level groupings. So this graph shows generally offenders have one or two separate clusters of locations they commit offenses at.

\section{[INSERT FIGURE 3 HERE]}

But this is generally a tale of spatial diversification for offenders over time. As one may have noticed prior from the minimum spanning tree diagram, offenders with many locations nearby will simply expand the tree into a greater area. Figure 4 plots the distance along the tree in meters for the top cluster (cutting off a few outliers with over 30 offenses in the time period) on the $Y$ axis against the number of offenses within the cluster on the $X$ axis. Points are again jittered to prevent them from being superimposed at the integer values of offenses. Here we can see the slight correlation, and no obvious groupings appear. Even at the smaller number of offenses the minimum spanning tree tends to be around 1,000 to 2,000 meters, which is a relatively wide footprint, and a much larger neighborhood than is typically considered for hot spot targeting. There is a particular irony in this that offenders with a longer history tend to have a wider dispersion of offense locations, thus theoretically would be harder to deter with a specific place based intervention. This has a relationship to Harcourt's (2010) point that the worst offenders are likely to be the ones the least likely to change their behavior in response to an intervention. But with top offender lists typically selection of the very top prolific offenders are chosen to the neglect of chronic offenders further down the list.

While such spatial footprints are likely to be biased estimates of the home range of offending, this bias seems very likely to underestimate the range of the offender, since the probability of arrest for a criminal event is typically very small. There are likely crime events nearby or outside the home range that are not observed in the police database, and the estimates are by necessity limited to this one jurisdiction. An overestimate of the home range might occur if offenders are more likely to be arrested when visiting faraway places, but that is the opposite of what is typically expected (i.e. more mobile offenders are less likely to be caught). In an evaluation linking offenders by DNA traces, Lammers (2014) finds that the probability of arrest is not related to how far apart an offenders crimes are on average.

\section{[INSERT FIGURE 4 HERE]}

\section{Places Profiles}

There are three particular characteristics of locations, based on the type and variety of people that offend there, that will make them potentially more attractive to either placed based interventions or person based interventions (focused specifically at one location). These characteristics are:

1. Places with fewer people committing most of the crimes will be more amenable to person based strategies.

2. Places with a larger proportion of chronic offenders may have a greater deterrent effect based on person based strategies.

3. Places that are more isolated are likely to have less spillover of people to other places. 
Several metrics developed to investigate question 1 were calculated for street units. Two of the easiest to interpret are the proportion of crimes committed by either the top offender at a street unit, or the top 10 offenders. Another metric that helps quantify this information on a continuous scale is a measure of diversity known as Shannon entropy (Peet, 1975). ${ }^{1}$ This measure is most notably used in ecology as a measure of the species diversity in particular locations, and so can be seen as a continuous measure of offender diversity at street units. Figure 5 displays these metrics at street units with over 8 crimes reported in the time period.

The figure in the top left corner shows the total number of offenses that the top 10 individuals at a street unit account for on the $Y$ axis, and the total number of offenses at that street unit on the $X$ axis. This metric can be motivated by if you could theoretically remove the top 10 offenders from a particular location, how much would crime be expected to decline at that location? It can be seen as one trends towards higher crime places, the top 10 offenders typically account for around 40 crimes, although several outliers can be spotted. The large outlier at over 100 crimes (which is a clearly visible outlier in several other plots as well) happens to associated with a psychiatric unit. At that location there end up being several prolific individuals who have many assaults.

The figures on the top and bottom right hand side display the proportion of all crimes that either the top 10 offenders or the top offender account for at a particular location. Note that this is 14 years of data, so a street unit with 140 crimes will only average around 10 offenses per year. If one uses this as a cutoff for high crime places, the total proportional contribution from the top 10 offenders is less than $20 \%$ at a street unit, and the proportional contribution from the top offender tends to be less than $10 \%$.

The proportion in the top 10 indicator happens to be highly correlated with the Shannon diversity index, with a correlation of -0.9. This can be seen as a continuous measure of the total diversity in offenders at a particular location, as opposed to relying a fixed number of offenders to calculate a proportional total. The plot in the lower left displays the Shannon Entropy measure on the $Y$ axis, with the total number of offenses on the $X$ axis. One can clearly see the maximum of the function as a hard line in the graph, which happens to be equal to the logarithm of the total number of offenses. In this case, entropy can be considered a measure of how predictable a person would be at a location. That is, if you knew a crime was committed at location $\mathrm{X}$, how likely is it that it was committed by person $\mathrm{Y}$ ? Locations that have the maximum entropy suggest that they are not predictable, you might as well just randomly pick one of the offenders who previously committed a crime at that location. These metrics were also mapped, although there were no obvious spatial patterns.

This suggests that although in absolute terms, focusing targeted interventions at hot people at places have potential to have an absolute reduction in crime in many places, such as taking the top 10 people may reduce total number of crimes around 40 in crime hot spots. Over a fourteen year time period, this corresponds to a reduction of on average under 3 crimes per year. Only examining events with an arrest or a suspected offender may greatly underestimate the number of crimes reduced though by taking away a particular offender - an offender may commit many crimes without being caught. So this is only a lower bound on that estimate.

\footnotetext{
${ }^{1}$ Shannon entropy is calculated as $S=-\sum_{i}^{n} p_{i} \cdot \log \left(p_{i}\right)$ where $p_{i}$ is the proportion of crimes offender $/$ commits at a street unit, and there are $n$ separate offenders at a street unit. So if a location has three offenders, and they each contribute $10 \%, 30 \%$, and $60 \%$ to the total number of crimes, the Shannon entropy will then be equal to $-[0.1 \cdot \log (0.1)+0.3 \cdot \log (0.3)+0.6 \cdot \log (0.6)] \approx 0.9$. In this example the natural logarithm is used.
} 
In relative terms though, this ends up being a small proportion of the total numbers of crimes at high crime micro places. Places with more crimes tend have a larger proportion of individuals committing the many offenses. This proportional estimate is less likely to be biased by having a large amount of offenses not observed, but relies on assumptions such as that the probability of capture (and re-capture) of arrested offenders is the same between offenders and the same over time within the same offender (Rossmo and Routledge, 1990). While heterogeneity between and within offenders surely exists, the size of it is less likely to greatly bias the estimates.

\section{[INSERT FIGURE 5 HERE]}

In regards to point 3, Places that are more isolated are likely to have less spillover of people. An example of isolation would be people that offend at location A tend to only offend at location A. There are two general ways that this can occur. One is that there are a limited number of offenders at that location and those offenders tend to be spatially limited in their offending. Another is that locations tend to be dominated by one-and-done offenders. The former, as has been seen by the other metrics, is not a pattern likely to occur. Chronic offenders tend to continually spatially expand their locations, and places with more offenses tend to have more offenders.

Calculating the proportion of one-and-done offenders simultaneously assesses question 2 as well, whether certain places have a larger proportion of chronic offenders, albeit with a very judicious interpretation of chronic offender. Figure 6 displays the total proportion of offenses at a street unit that are committed by one-and-done offenders. That is, if a location had a total of 100 offenses, and 30 of them were committed by individuals that had no other arrest history, the proportion would be $30 \%$. The overall proportion weighted by offenses is $16.8 \%$, and the contour line shows the upper and lower $99 \%$ confidence intervals based on the exact Clopper-Pearson interval for a given total number of offenses (Spiegelhalter, 2005). Outlier points that have a high proportion of one-and-done offenders are shown as red dots, and those with fewer than expected are shown as blue dots.

Figure 7 maps out these outlier locations, using the same color scheme and sizing the points according to the total number of offenses. The map only shows locations with 10 or more total offenses over the time period. These show several prominent clusters for the metric. Clusters of blue locations (fewer than expected one-and-done) tend to concentrate in several residential neighborhoods, Arbor Hill and South End, which are known higher crime areas. The red dots in the central area of the city cluster around several schools, Albany High as well as the college of St. Rose. This area is mixed commercial/residential, with a high proportion of student housing. The point in the left most part of the map is a commercial shopping area that includes a Wal-Mart. The smaller cluster of red dots in the eastern part of the city is an entertainment area on Pearl Street that includes several popular bars.

\section{[INSERT FIGURE 6 AND FIGURE 7 HERE]}

These clusters allow some hypothesizing about the nature of places with a larger proportion of chronic offenders. Commercial locations, and places where more young people tend to congregate, have a higher proportion of one-and-done offenders. In contrast, residential neighborhoods with high crime areas tend to have a lower proportion of one-and-done offenders. For the former, person based strategies at these high crime micro places are unlikely to be effective. One might be better off developing strategies to deter crime before it happens, as one-and-done offenders perhaps are more 
easily deterred than more chronic offenders (Harcourt, 2010). The latter places though show more promise for strategies to intervene with more chronic offenders.

\section{Neighborhoods}

The final exploration undertaken in this study is whether the connections between people and places conforms to particular definitions of neighborhoods in Albany or whether they form spatially regular neighborhoods at all. This not only has utility for criminological theory, which often describes spatial processes and how they impact crime via neighborhood level processes, but also for police departments. The analysis so far at the street unit level shows a wide amount of variability, if one can identify functional neighborhoods in which many people share links, it makes a people at places strategy simpler. That is, looking at the micro unit of a street section may introduce needless variance into the analysis. There may be ways to define spatial units of analysis though that produce more homogenous neighborhoods to target people based strategies at.

The first issue is how to relate the bipartite graph between people and places to only a graph of links between places. To address this, Breiger (1974) describes an algorithm to transform a bipartite graph into a weighted graph with only a single type of node. While the original article uses matrix algebra, a simple description of the algorithm in terms of multiplying and counting edge weights in the original bipartite graph is depicted in Figure 8. In the first set of nodes, Person A committed two crimes at Place 1 and 3 crimes at Place 2. To aggregate these to direct connections between Place 1 and Place 2, one multiplies the edge weights on the left hand side. So in the first row of the diagram, Person A's offending pattern results in a weight of 6 between Place 1 and Place 2. Place 1 and Place 2 can share additional offenders as well, and here we see that Person B had 1 offense at Place 1 and 3 offenses at Place 2, resulting in a total weight of 3 . In this simplified network, one would then add the two weights on the right hand side together, so the final edge weight between Place 1 and Place 2 would total 9 in this example.

\section{[INSERT FIGURES 8, 9 AND 10 HERE]}

The flows are normalized by taking the natural log of the ratio of observed links divided by the expected number of links if street units were chosen at random according to their overall prevalence (Guo, 2009). For a simplified example, if in a city location A had an overall probability of a crime being committed there at $10 \%$, and location $B$ had $5 \%$, there expected edge weight would be $0.10^{*} 0.05$. The observed proportion of edges between those places in the dataset is then divided by this expected proportion. Taking the logarithm of this ratio produces a very smooth distribution that is right skewed and has a mean of 1 , as can been seen in Figure 9 . This shows that places tend to be more connected that you would expect simply given their marginal proportions, as the expected value of the ratio would be zero.

The connections themselves are highly complicated though, and Figure 10 displays those links with a normalized edge weight of over 5 in a flow map - thus places with 5 times more connections than would be expected. Edges are drawn very thin and transparent, to better show the distribution of the flows (Wheeler, 2015). Various combinations of selecting and drawing only certain links were tried, but the map was always very complicated. The flows between street units in Albany is very connected, no matter how you slice the data. Similarly drawing locations that had negative ratios (that is places with fewer connections than expected) showed no obvious spatial patterns either. One might expect that barriers, such as major arterial roads or informal neighborhood boundaries might prevent connections between places (Reynald et al., 2008; Rengert, 2004), but no such barriers were obvious. This 
subsequently shows that there are many heterogeneous connections between places, and that the network of places is entirely connected. The connections between places and people is subsequently small world.

Often studies treat the place where offenders commit their crime and the place where they live as synonymous measures, citing that the journey to crime distance tends to be very short. While the fact that the journey to crime tends to be short (Rossmo, 2000), offenders are clearly are not spatially limited to only one neighborhood in this dataset. Such diffusion calls into question treating fixed geographical regions as bubbles that determine every individual's exposure, and network based contextual measures may be much more appropriate for many criminological research designs (Hipp et al., 2012).

To further make sense out of this data, a clustering algorithm on the original bipartite graph was conducted. The algorithm used is described in Clauset et al. (2004). It was not originally designed for bipartite graphs, but it works just the same as in the case for graphs with a single type of node. Just as importantly, it works fairly quickly for large graphs, which more intensive algorithms would not be feasible on this dataset. Clustering algorithms on graphs can be described as detecting smaller subsets of the graph that maximize connections within and minimize connections between the different subsets. These subsets are then referred to as communities, and so the process is often called community detection. While some clustering algorithms can be amended to only return spatially adjacent clusters (Steenbeek and Kreis, 2015), this algorithm can return spatially disparate areas into the same cluster. This allows exploration of clusters of points in the same community, but also assessment of connected areas not within similar territories. Which is a result not entirely unexpected via crime pattern theory (Brantingham and Brantingham, 1993).

The community detection algorithm, when applied to the bipartite graph, generated 52 communities with more than one location. The spatial locations of the 9 communities with over 90 street units are drawn in Figure 11. One can see that while they do show some level of spatial consistency, they are often overlapping and embedded in a set of complicated patterns (and the same is true for the other communities not displayed). Merging offenders with gang affiliations, several communities were predominately associated with one particular gang. But even then only a small proportion of all offenses within a community were committed by a gang member. For example, in community 22 , of the 3,640 offenders committing crime in this cluster, 511 of them are associated with a gang (14\%). Of those 511, 370 were associated with the Uptown gang (72\%). For community 9, of the 3,434 offenders, 431 were associated with a gang. Of those, $372(86 \%)$ were associated with the Downtown gang. Examining the spatial distribution of these two communities, while they cluster in their respective expected neighborhood areas, each territory is fairly widespread, and has several examples extending into neighboring gang areas.

[INSERT FIGURE 11 HERE]

\section{Conclusion}

This work attempted to identify the overlap between hot people and hot places. The motivation is that these are the two overarching types of intelligence led interventions by the police intending to reduce crime. This exploratory work focused on three separate themes. 1) Identifying whether individuals showed spatial clustering in their offenses, and so they would be amenable to place based approaches. 2) Whether certain places had a large number of chronic offenders, and so a place may be amenable to 
a person based strategy. 3) Whether natural neighborhoods could be identified in the data, and whether those locations coincided with known neighborhood boundaries in Albany.

The result of examining each question produces a much more complicated pattern than the previous literature on hot spots and hot people. Chronic offenders tend to show high mobility, suggesting place based approaches are potentially going to displace chronic offenders to different locations, and not necessarily locations spatially nearby. While choosing a new location for an offense is related to prior locations, spatial heterogeneity in offense locations and continually expanding their offending territory tends to be the norm for most chronic offenders. In short, a single place based strategy seems unlikely to work on a particular offender.

Places also tend to show a high variety of offenders, and so a person based strategy, such as focusing on arrests of a few individuals, are unlikely to result in large declines in crime at any particular hot spot. This suggests that crackdown like interventions, which tend to focus on arresting individuals, are only likely to be effective in reducing crime if they increase general deterrence. The specific deterrence associated with arresting a few chronic offenders is not likely to put much of a dent in overall crime counts at hot spots due to their diversity of offenders. This suggests that successful prior interventions incorporating people at places strategies (Corsaro et al., 2012; Groff et al., 2015; Uchida \& Swatt, 2013) likely produced crime reductions not only among the targeted offenders, but among the larger population of potential offenders. This is similar to diffusion of benefits for an intervention, but instead of geographic diffusion it is diffusion among non-targeted individuals.

Finally, it was examined whether natural areas or neighborhoods could be identified among the connected network of people and places. It was shown that the entire city was highly connected, with larger than expected connections between many different areas. While a community detection routine identified a number of clusters, they tended to show dispersal over very wide spatial areas. This suggests that offending patterns are not dictated by neighborhood (or other) boundaries, but in the aggregate tend to be diverse areas across the city.

In total, these three findings suggest that weaving together person and place based strategies are not likely to be as fruitful as either strategy is individually. But, person or place based policing strategies can take into account either fact to potentially improve either intervention. For example, hot spots of crime that have a higher proportion of one-and-done offenders may be less amenable to arrest based strategies. This is because they are high crime because of a continual flow of new offenders. Arrest based strategies are likely to only have a short term general deterrent effect (Sherman et al., 1995), and so the flow of new offenders may only be deterred for a short time period. But, it is likely that new offenders are more at the margins of committing a crime to begin with, so less invasive interventions like crime prevention through environmental design or problem oriented policing strategies may have more success.

For chronic offender strategies, while offenders tend to continually expand their offender territories, they committed the majority of their crimes in one area. Unfortunately, this area tended to be large. While knowing an offenders typical geographic dispersion is important for intelligence purposes for the police department, it does not immediately suggest a simple geographic strategy to deter the offender from committing future crimes. 


\section{Citations}

Bowers, K., Johnson, S., Guerette, R., Summers, L., and Poynton, S. (2011). Spatial displacement and diffusion of benefits among geographically focused policing initiatives: A meta-analytical review. Journal of Experimental Criminology 7(4):347-374.

Braga, A., Apel, R., and Welsh, B. (2013). The spillover effects of focused deterrence on gang violence. Evaluation Review 37(3-4): 314-342.

Breiger, R. L. (1974). The duality of persons and groups. Social Forces, 53(2):181-190.

Brantingham, P. L. and Brantingham, P. J. (1993). Nodes, paths and edges: Considerations on the complexity of crime and the physical environment. Journal of Environmental Pyschology, 13(1):3-28.

Brantingham, P.J. and Tita, G.E. (2008). Offender mobility and crime pattern formation from first principles, pages 193-208. Artificial crime analysis systems: Using computer simulations and geographic information systems. Ed. By Liu, L. and Eck, J. Hershey, PA: Idea Press.

Brantingham, P. J., Tita, G. E., Short, M. B., and Reid, S. E. (2012). The ecology of gang territorial boundaries. Criminology 50(3): 851-885.

Clauset, A., Newman, M., and Moore, C. (2004). Finding community structure in very large networks. Physical Review E, 70(6):066111+.

Cleveland, W.S. and Devlin, S.J. (1988). Locally weighted regression: An approach to regression analysis by local fitting. Journal of the American Statistical Association 83(403): 596-610.

Corsaro, N., Hunt, E. D., Hipple, N. K., and McGarrell, E. F. (2012). The impact of drug market pulling levers policing on neighborhood violence. Criminology \& Public Policy, 11(2):167-199.

Eck, J. and Spellman, W. (1987). Problem-solving: Problem-oriented policing in Newport News. Police Executive Research Forum: Washington, D.C.

Ester, M., Kriegel, H.-p., Jorg, S., and Xu, X. (1996). A density-based algorithm for discovering clusters in large spatial databases with noise. Kdd 96(34): 226-231.

Felson, M., Andresen, M. A., and Frank, R. (2011). Mobility polygons and the geometry of co-offending, pages 3-15. Patterns, Prevention, and Geometry of Crime. Ed. Andresen, M.A. and Kinney, J.B. Routledge, New York, NY.

Frank, R., Andresen, M. A., and Brantingham, P. L. (2012). Criminal directionality and the structure of urban form. Journal of Environmental Psychology, 32(1):37-42.

Frank, R., Andresen, M. A., and Felson, M. (2012). The geodiversity of crime: Evidence from British Columbia. Applied Geography, 34:180-188.

Granovetter, M. (1973). The strength of weak ties. American Journal of Sociology 78(6):1360-1380. 
Groff, E., Ratcliffe, J., Haberman, C., Sorg, E., Joyce, N., Taylor, R. (2015). Does what police do at hot spots matter? The Philadelphia policing tactics experiment. Criminology 53(1): 23-53.

Guerette, R. and Bowers, K. (2009). Assessing the extent of crime displacement and diffusion of benefits: A review of situational crime prevention evaluations. Criminology 47(4):1331-1386.

Guo, D. (2009). Flow mapping and multivariate visualization of large spatial interaction data. IEEE Transactions on Visualization and Computer Graphics 15(6): 1041-1048.

Harcourt, B. (2010). Moving beyond profiling: The virtues of randomization, pages 505-524. Race, Ethnicity, and Policing. Rice, S.K., and White, M.D. New York University Press New York, NY.

Hering, A. S. and Bair, S. (2014). Characterizing spatial and chronological target selection of serial offenders. Journal of the Royal Statistical Society Series C, 63(1):123-140.

Hipp, J.R., Faris, R.W., Boessen, A. (2012). Measuring 'neighborhood': Constructing network neighborhoods. Social Networks 34(1): 128-140.

Iwanski, N. and Frank, R. (2013). The evolution of a drug co-arrest network. In Crime and Networks ed. Morselli, C. pg. 52-80. Routledge: New York.

Jacobs, B. A. (2010). Serendipity in robbery target selection. The British Journal of Criminology, 50(3):514-529.

Johnson, S. D., Summers, L., and Pease, K. (2009). Offender as forager: A direct test of the boost account of victimization. Journal of Quantitative Criminology, 25(2):181-200.

Kadushin, C. (2012). Understanding social networks: Theories, concepts, and findings. Oxford University Press: New York, NY.

Lammers, M. (2014). Are arrested and non-arrested serial offenders different? A test of spatial offending patterns using DNA found at crime scenes. Journal of Research in Crime and Delinquency 51(2): 143-167.

Lammers, M., Menting, B., Ruiter, S., and Bernasco, W. (2015). Biting once, twice: The influence of prior on subsequent crime location choice. Criminology, 53(3): 309-329.

Lantz, B., Ruback, R. (2015). A networked boost: Burglary co-offending and repeat victimization using a network approach. Crime \& Delinquency, Online First.

McGloin, J. M. (2005). Policy and intervention considerations of a network analysis of street gangs. Criminology \& Public Policy, 4(3):607-635.

McGloin, J. M. and Kirk, D. S. (2010). An overview of social network analysis. Journal of Criminal Justice Education, 21(2):169-181.

Mizutani, F. and Jewell, P. A. (1998). Home-range and movements of leopards (Panthera pardus) on a livestock ranch in Kenya. Journal of Zoology, 244(2):269-286. 
Morselli, C. (2010). Assessing vulnerable and strategic positions in a criminal network. Journal of Contemporary Criminal Justice 26(4):382-392.

Morselli, C. (2012). Assessing network patterns in illegal firearm markets. Crime, Law and Social Change 57(2):129-149.

Papachristos, A. V. (2011). The coming of a networked criminology. Measuring Crime \& Criminality: Advances in Criminological Theory, 17:101-140.

Ratcliffe, J. H. (2008). Intelligence-led policing. Willan Publishing. Portland, OR.

Rengert, G.F. (2004). The journey to crime. In Punishment, places and perpetrators: Developments in criminology and criminal justice research. Ed. Bruinsma, G., Elffers, H., and de Keijser, J.W. p 169-181.

Rengert, G.F. and Wasilchick, J. (2000). Suburban Burglary: A tale of two suburbs. Charles C. Thomas. New York, NY.

Reid, A. A., Frank, R., Iwanski, N., Dabbaghian, V., and Brantingham, P. (2014). Uncovering the spatial patterning of crimes: A criminal movement model (CriMM). Journal of Research in Crime and Delinquency 51(2):230-255.

Reynald, D.M., Averdijk, M., Elffers, H., and Bernasco, W. (2008). Do social barriers affect urban crime trips? The effects of ethnic and economic neighborhood compositions on the flow of crime in the Hague, the Netherlands. Built Environment 34(1): 21-31.

Rossmo, D.K. (2000). Geographic Profiling Boca Rotan, FL: CRC Press.

Rossmo, D.K. and Routledge, R. (1990). Estimating the size of criminal populations. Journal of Quantitative Criminology 6(3): 293-314.

Sherman, L., Rogan, D., Edwards, T., Whipple, R., Shreve, D., Witcher, D., Trimble, W., Velke, R., Blumberg, M., Beatty, A., and Bridgeforth, C. (1995). Deterrent effects of police raids on crack houses: A randomized, controlled experiment. Justice Quarterly 12(4): 755-781.

Sparrow, M. K. (1991). The application of network analysis to criminal intelligence: An assessment of the prospects. Social Networks, 13(3):251-274.

Spelman, W. (1990). Repeat Offender Programs for Law Enforcement. Police Executive Research Forum. Washington, D.C.

Spelman, W. (1995). Criminal careers of public places. Crime Prevention Studies 4:115-144.

Spiegelhalter, D.J. (2005). Funnel plots for comparing institutional performance. Statistics in Medicine 24(8): 1185-1202.

Steenbeek, W. and Kreis, C. (2015). Where broken windows should be fixed: Toward identification of areas at the tipping point. Journal of Research in Crime and Delinquency 52(4): 511-533. 
St. Jean, P. (2007). Pockets of crime: Broken windows, collective efficacy, and the criminal point of view. Chicago University Press: Chicago, IL.

Tayebi, M. A., Frank, R., and Glässer, U. (2012). Understanding the link between social and spatial distance in the crime world. In Proceedings of the 20th International Conference on Advances in Geographic Information Systems, SIGSPATIAL '12, pages 550-553, New York, NY, USA. ACM.

Tillyer, M. S. and Kennedy, D. M. (2008). Locating focused deterrence approaches within a situational crime prevention framework. Crime Prevention and Community Safety: An International Journal, 10(2):75-84.

Tita, G. E. and Radil, S. M. (2011). Spatializing the social networks of gangs to explore patterns of violence. Journal of Quantitative Criminology, 27(4): 521-545.

Uchida, C. D. and Swatt, M. L. (2013). Operation LASER and the effectiveness of hotspot patrol: A panel analysis. Police Quarterly, 16(3):287-304.

Van Mastrigt, S. and Carrington, P. (2014). Sex and age homophiliy in co-offending networks:

Opportunity or preference. In Crime and Networks ed. Morselli, C. pg. 28-51. Routledge: New York.

Weisburd, D. (2015). The law of crime concentration and the criminology of place. Criminology, 53(2):133-157.

Weisburd, D. and Green, L. (1994). Defining the street-level drug market. In Drugs and crime: Evaluating public policy initiatives. Ed. MacKenzie, D. and Uchida, C. pg. 61-76. Sage. London.

Wheeler, A. (2012). The moving home effect: A quasi experiment assessing effect of home location on the offence location. Journal of Quantitative Criminology 28(4): 587-606.

Wheeler, A. (2015). Visualization techniques for journey to crime flow data. Cartography and Geographic Information Science 42(2): 149-161.

Wilkinson, L. (2005). The Grammar of Graphics. Springer: New York, NY.

Wilkinson, L. and Wills, G. (2008). Scagnostic distributions. Journal of Computational and Graphical Statistics, 17(2):473-491.

Wu, X. and Grubesic, T. (2010). Identifying irregularly shaped crime hot-spots using a multiobjective evolutionary algorithm. Journal of Geographical Systems, 12(4):409-433. 


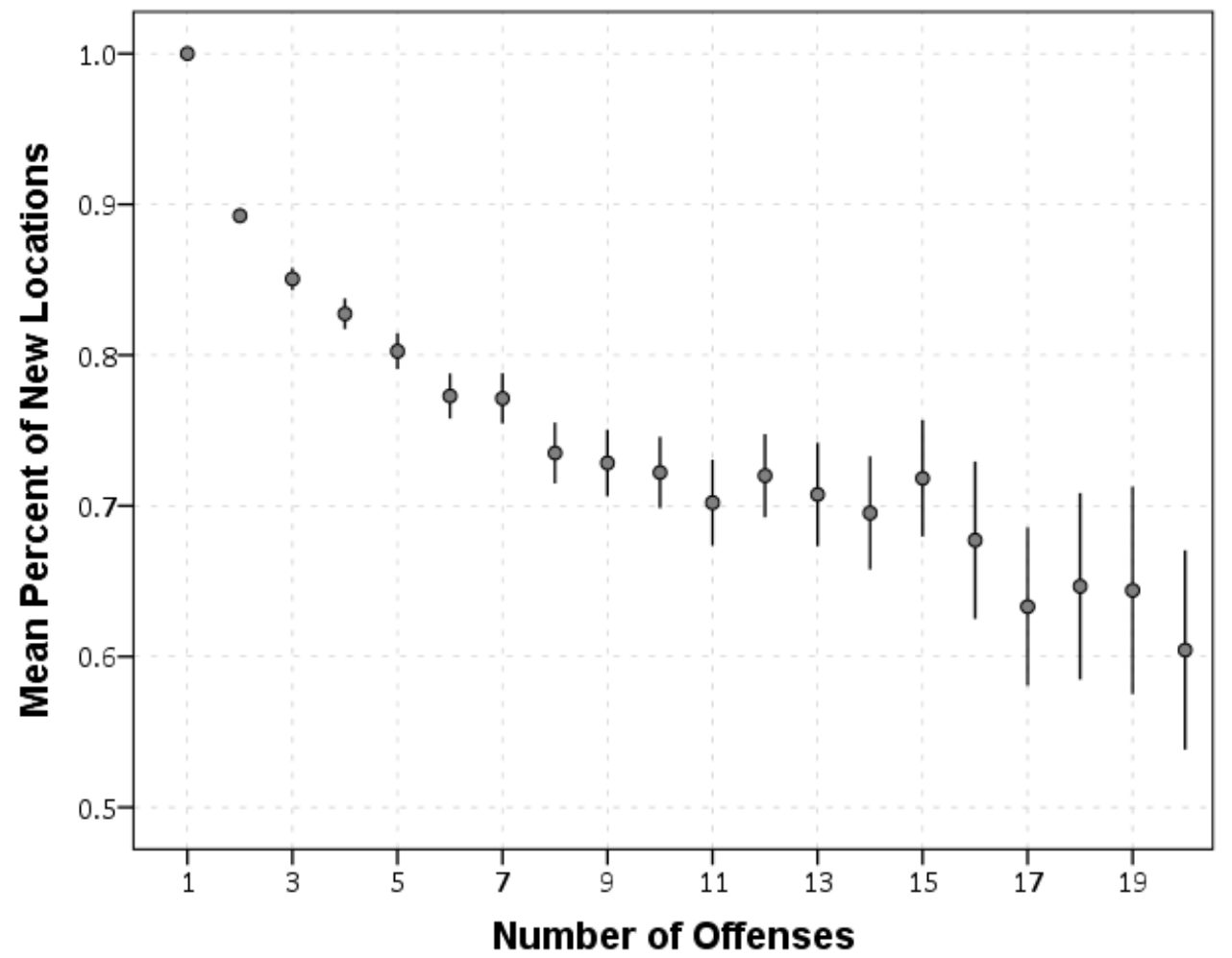

Figure 1: Average Percent of new locations per number of offenses in the sample. Error bars at plus and minus two standard errors of the percentage 

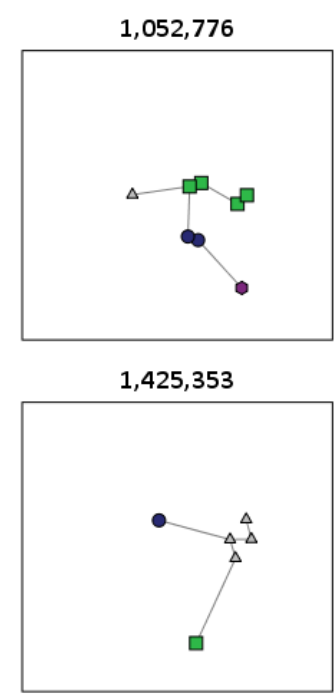

$1,760,631$
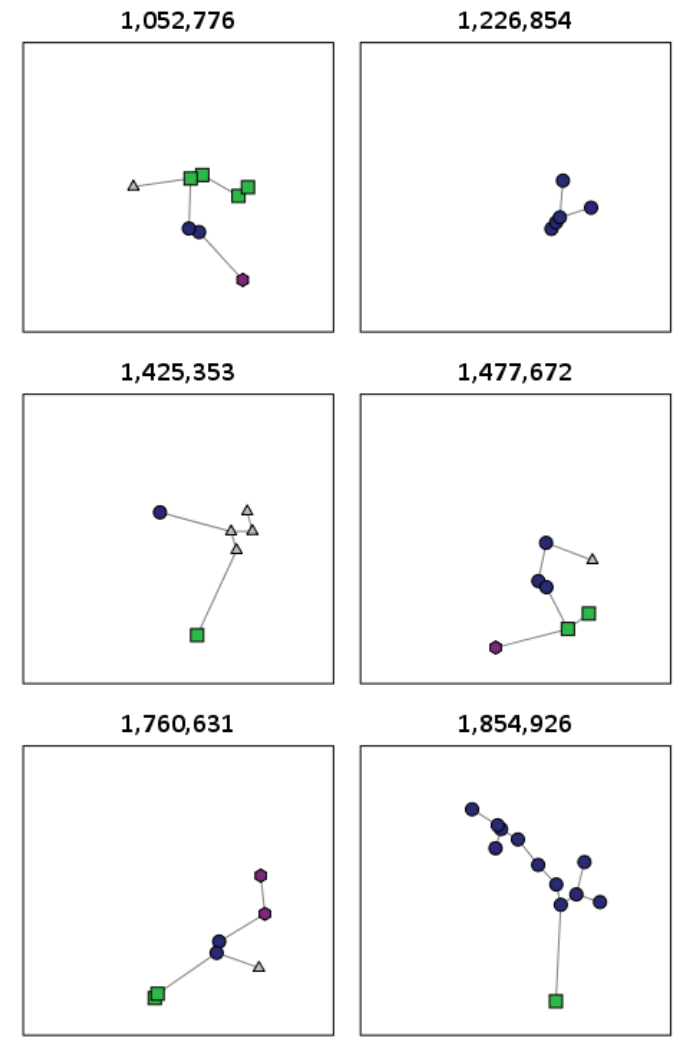

$1,477,672$

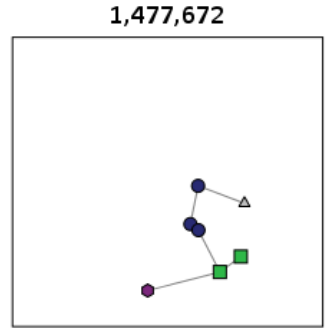

$1,854,926$

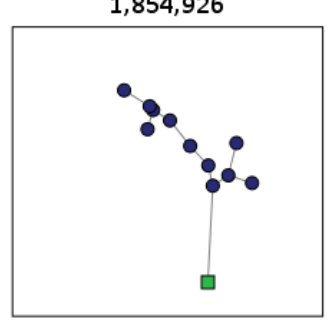

$1,228,120$

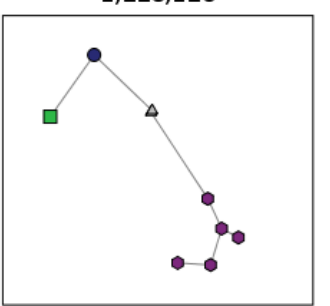

$1,482,057$

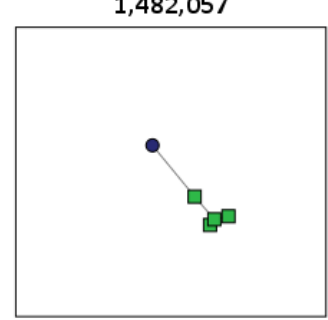

$1,855,591$

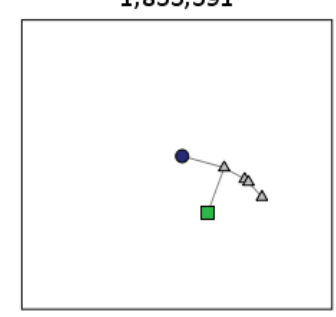

$1,411,282$

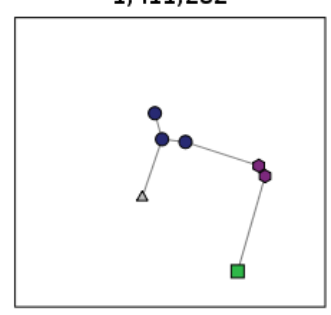

$1,495,472$

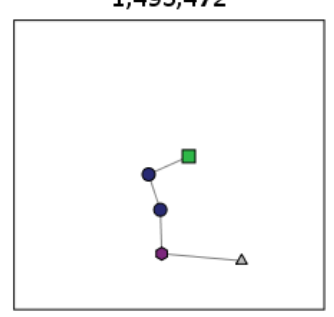

$1,956,967$

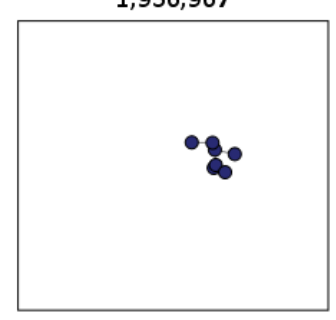

Figure 2: Random sample of offender footprints with minimum spanning tree 


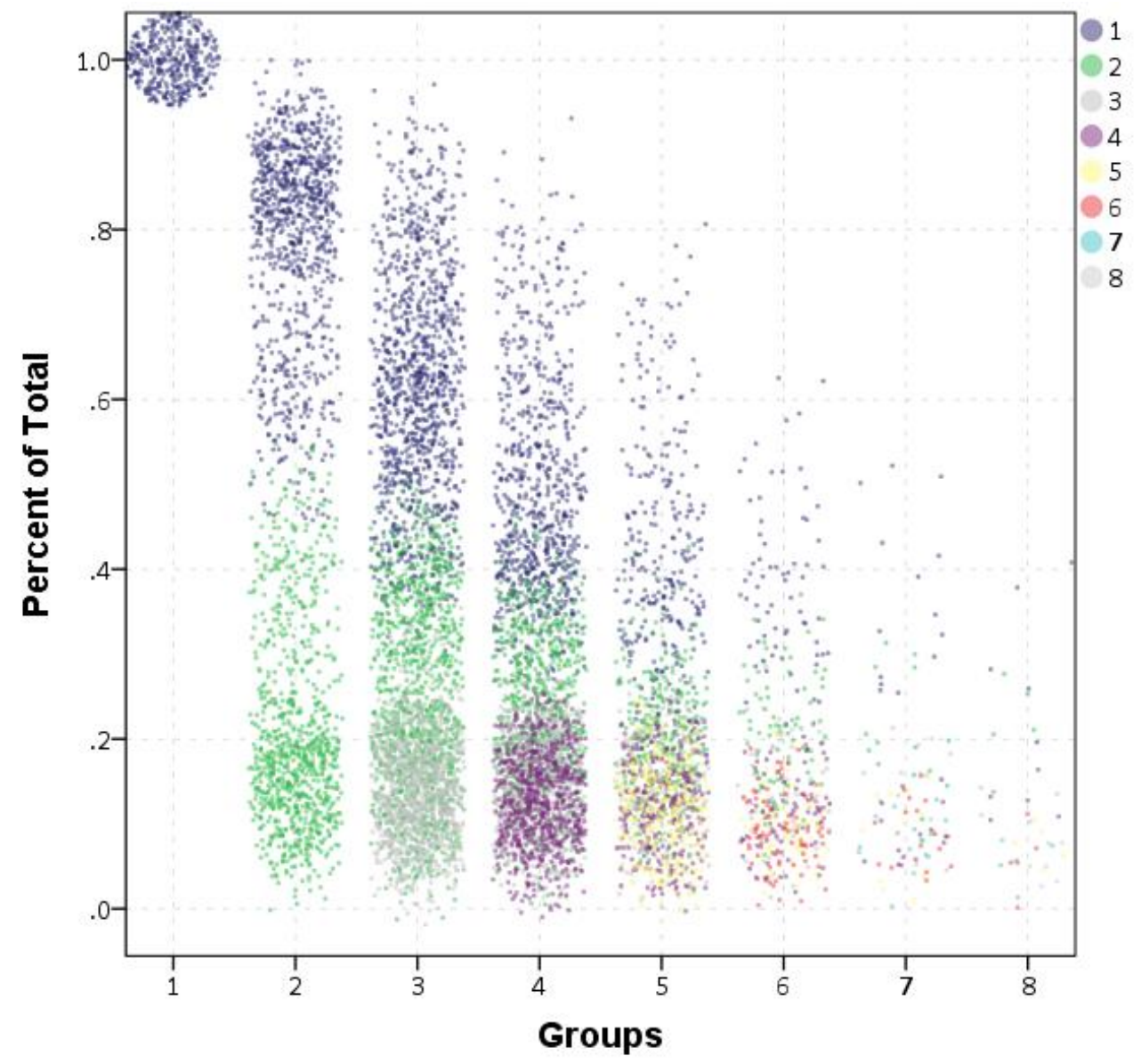

Figure 3: Percent of Crimes within Each Cluster 


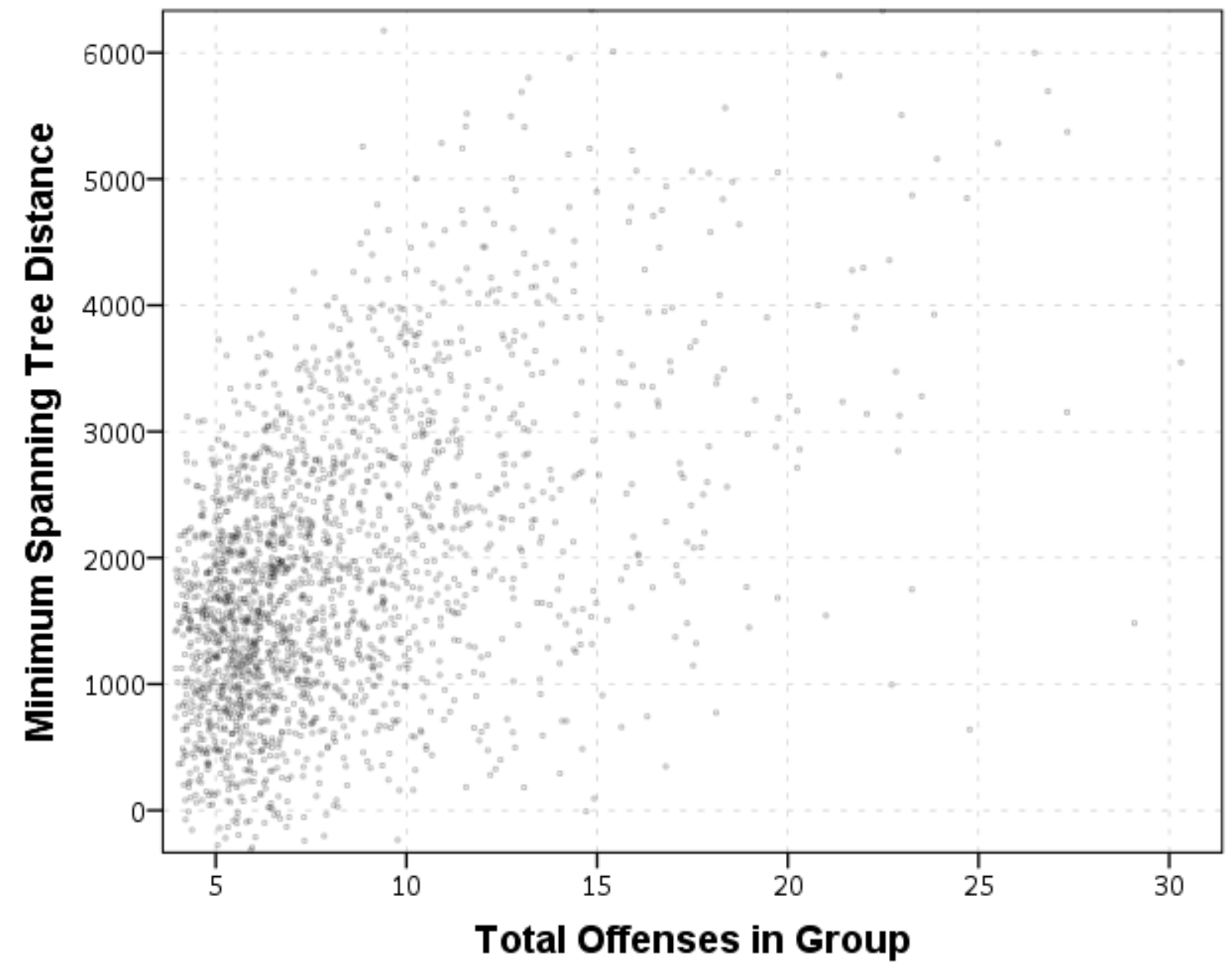

Figure 4: Minimum spanning tree distance per cluster size 

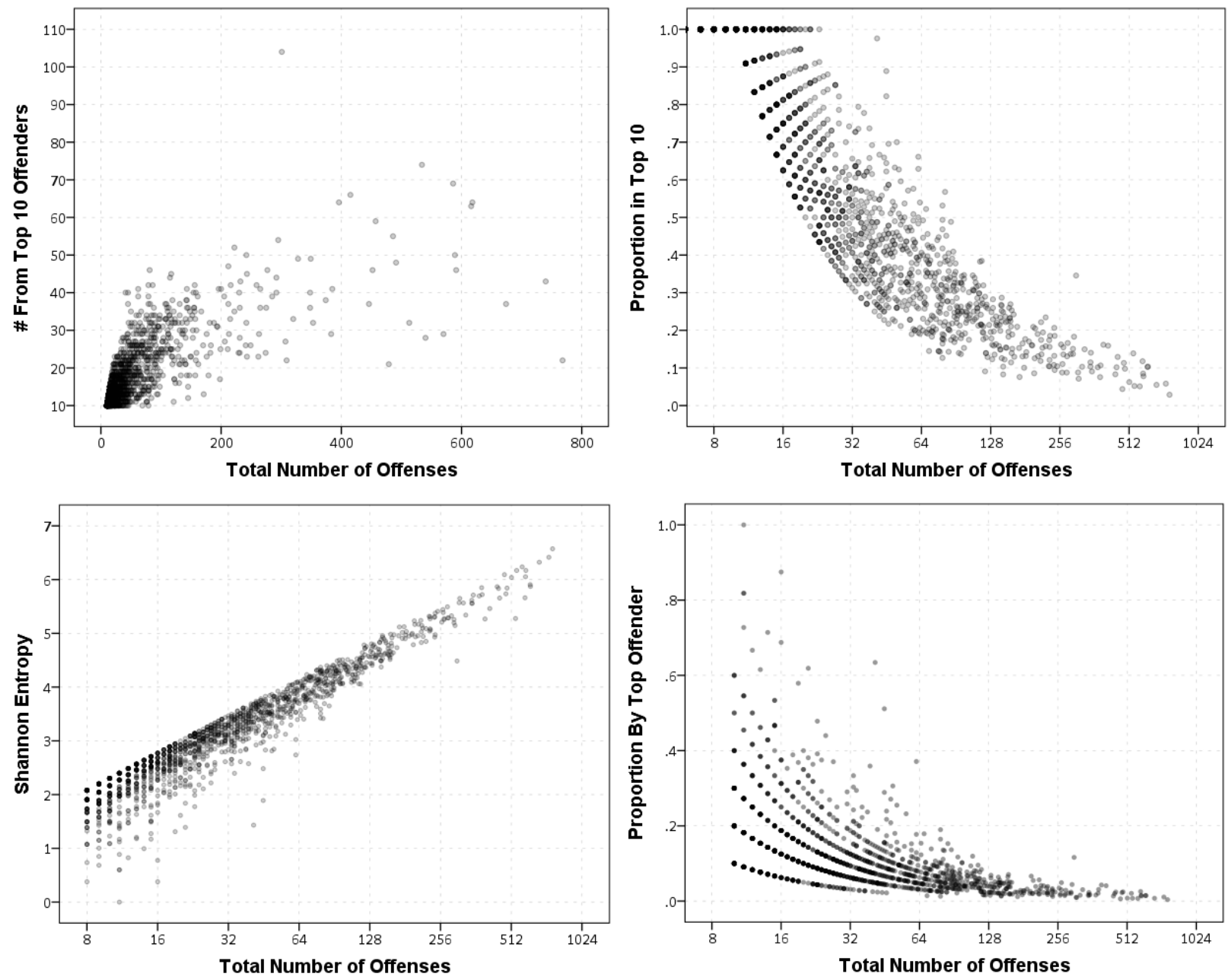

Figure 5: Street Unit Metrics 


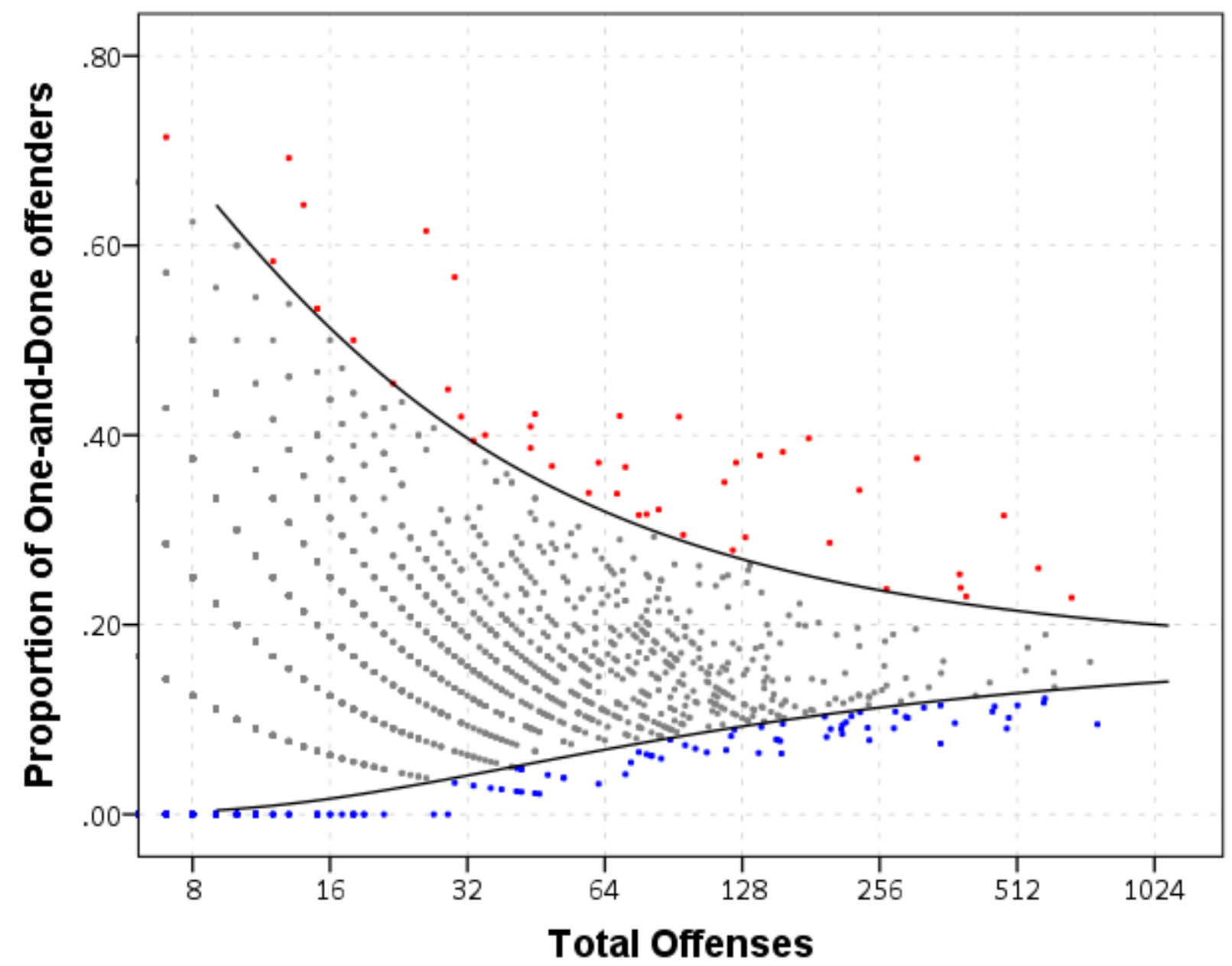

Figure 6: Proportion of Offenses committed by One-and-Done offenders at Street Units. Lines are 99\% confidence intervals around the overall proportion of $17 \%$. 


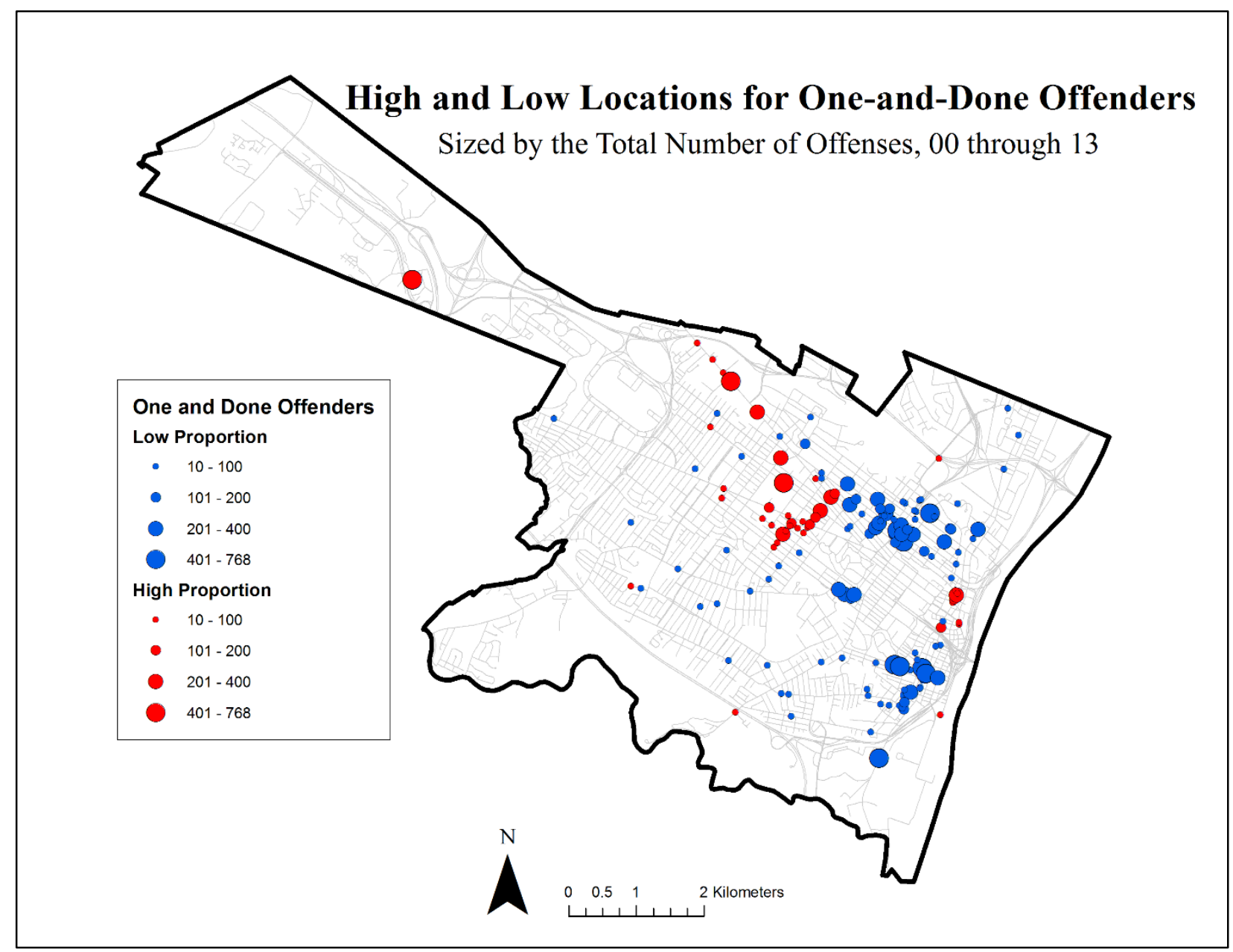

Figure 7: Map of High and Low Proportion of One-and-Done Offenders, based on Figure 6 


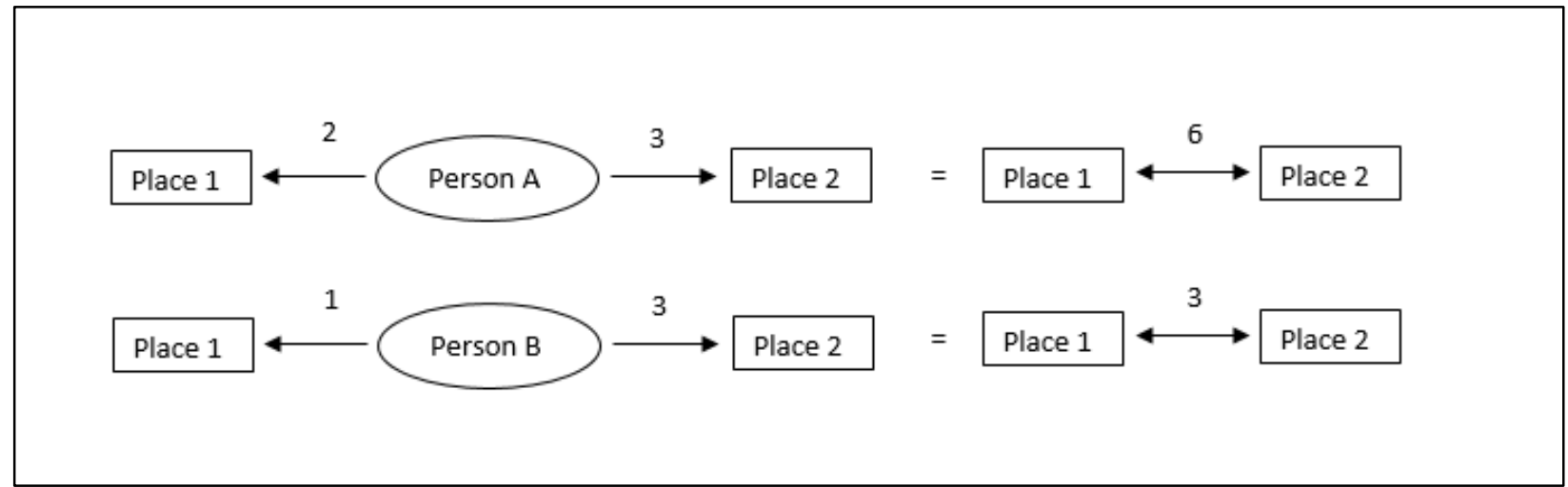

Figure 8: Description of the algorithm to turn a weighted bipartite graph into a weighted graph with a single type of node (Breiger, 1974). One multiples the weights along the path for each Place/Person/Place combination, and the final edge weight is the sum of those combinations. The final weight between Place 1 and Place 2 will be 6+3=9 in this example. 


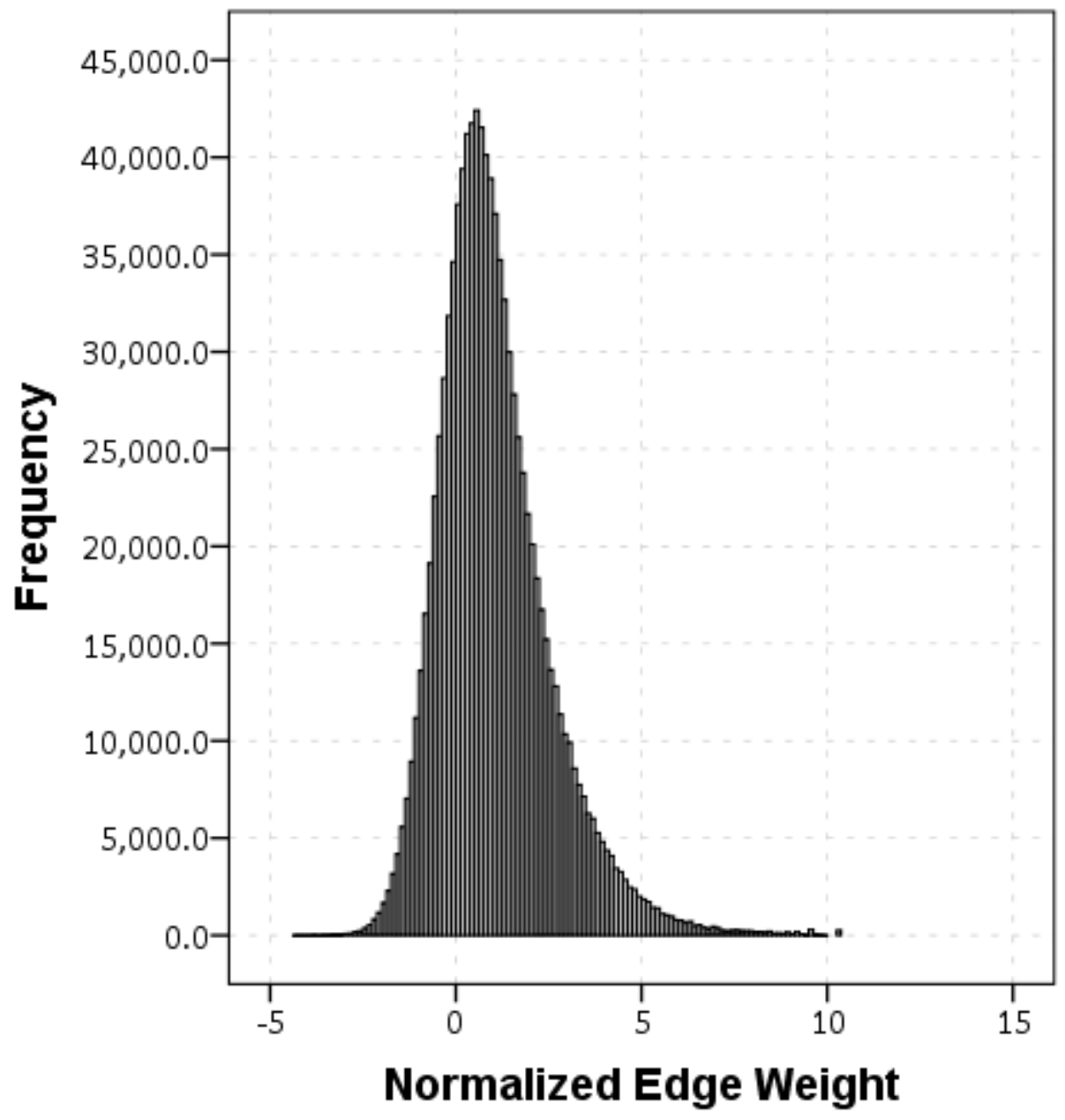

Figure 9: Edge Weights between Street Units, normalized by dividing by the observed proportion divided by the expected proportion and taking the natural logarithm 


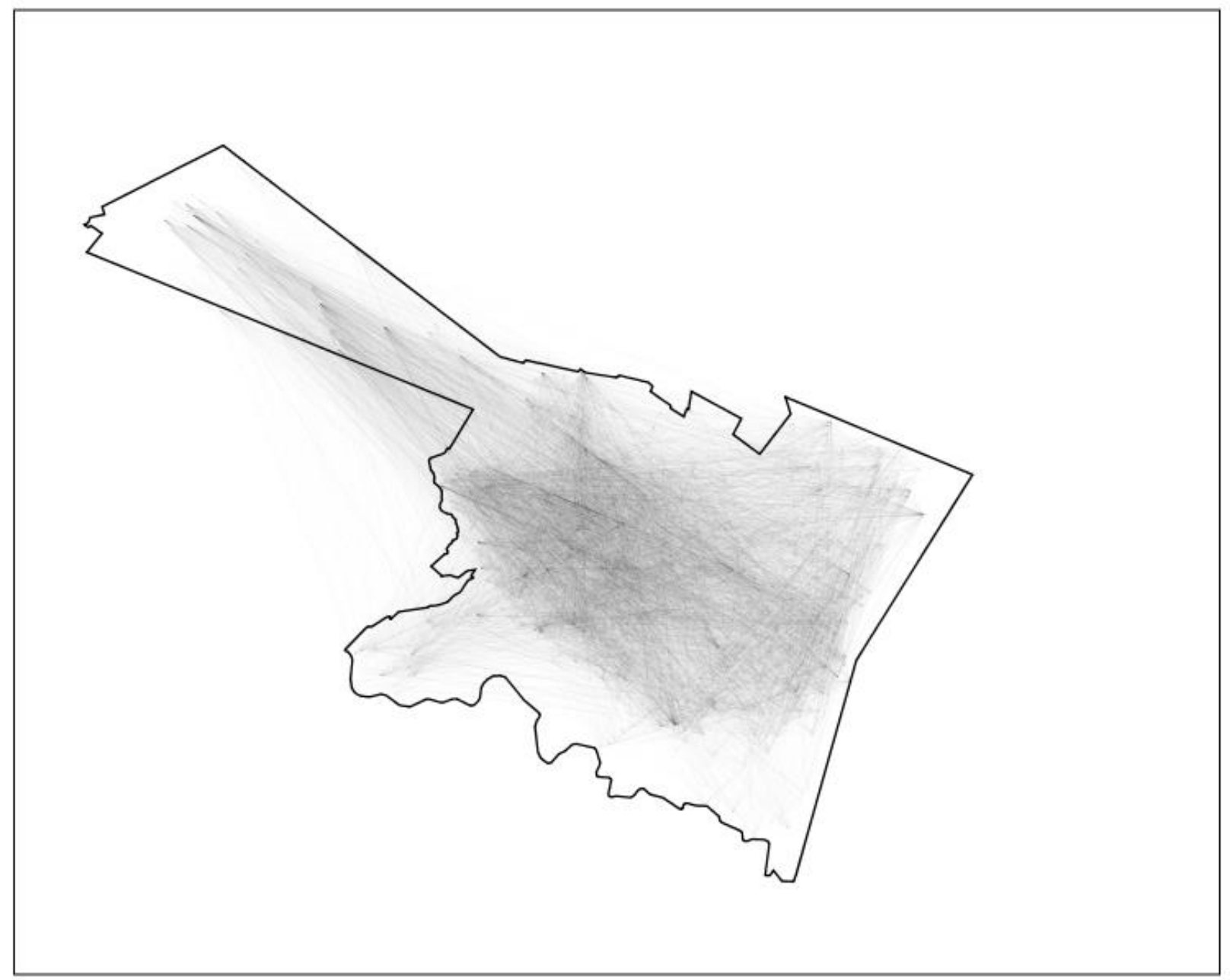

Figure 10: Flow map of Edge Weights with a normalized value of over 5 

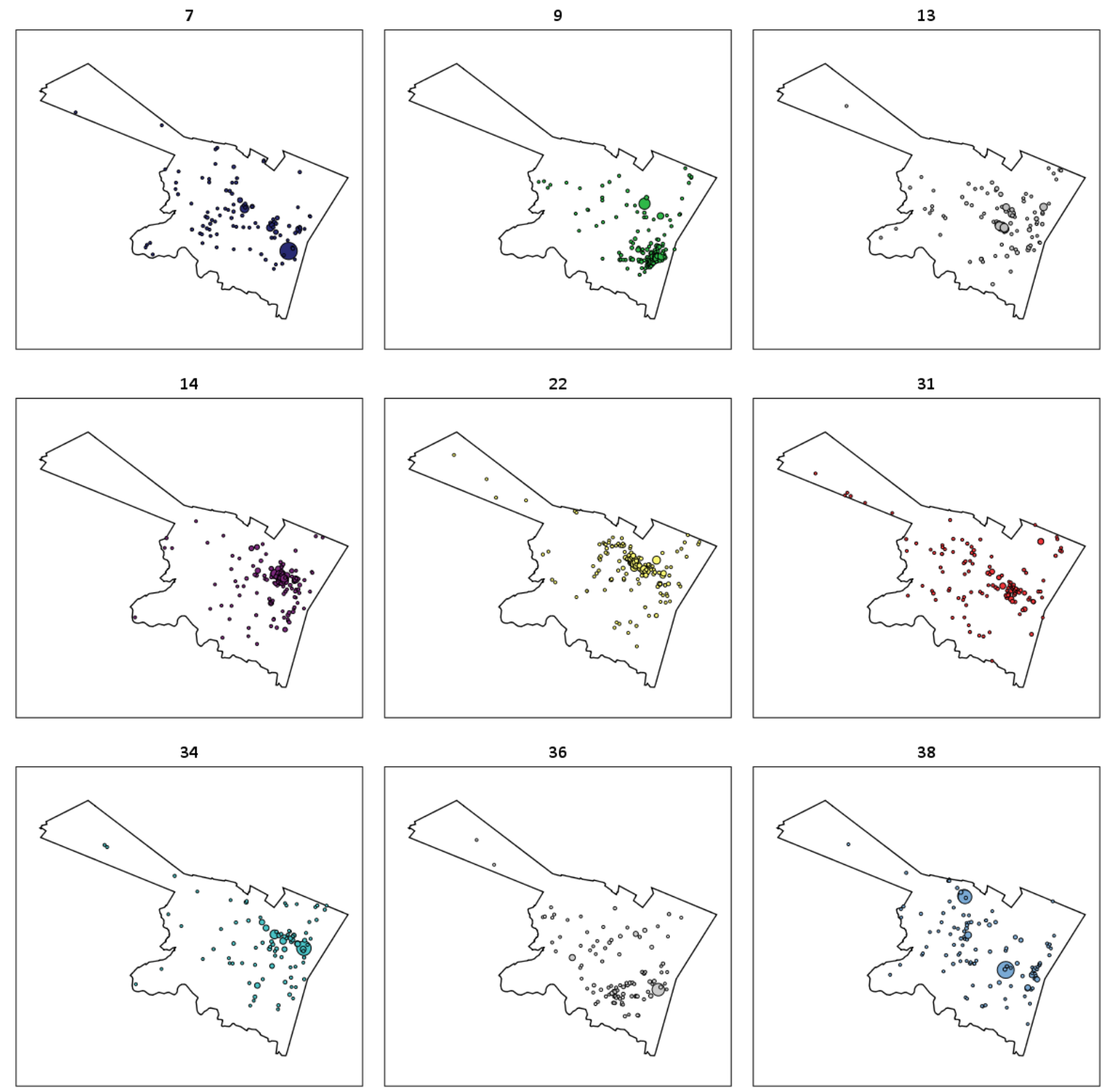

Figure 11: Map of Communities Detected from Bipartite Graph (Communities with 90 or more street units) 